\title{
Green, Eco, Innovative Design, and Manufacturing Technology of a 1-Ton per Batch Municipal Solid Waste Incinerator
}

\author{
Somrat Kerdsuwan \\ The Waste Incineration Research Center, Department of Mechanical and Aerospace Engineering, Faculty of Engineering, Science and \\ Technology Research Institute, King Mongkut's University of Technology North Bangkok, Bangkok, Thailand
}

\begin{abstract}
The thermal treatment of waste by incineration is considered an ultimate solution in order to get rid of waste properly by using the combustible properties of waste and transforming them into inert form and gaseous emission, with the main advantage of a huge reduction in mass and volume of treated waste, destruction of the dangerous components in waste, and obtaining green and clean energy from the exothermal reaction from the completed combustion process. In order to achieve the main goal of incineration, a good design, construction, supervision, and intensive operation and maintenance must be taken into account, especially for the small-scale incinerator. This research will deal with the green, innovative, and eco design and manufacturing technology of a 1ton per batch municipal solid waste (MSW) incinerator. The concept design of the incinerator will focus on the design of the feeding process where only one batch of waste will be discharged into the combustion chamber at one time instead of the semi-feed process, as found in the conventional incinerator. This will ease the operation of the operator and reduce the operating cost. Moreover, the innovative design includes the redesign of combustion air injection into either the primary or secondary combustion chamber in order to achieve the 3Ts of combustion (time, temperature. and turbulence). This design can eliminate the use of an auxiliary burner in the primary combustion chamber. Rethinking the innovative design of using recirculation hot flue gas for preheating of wet garbage in order to pre-dry the waste before combustion is also taken into account. The manufacturing process of the wall composition as well as other parts of the incinerator are also examined.
\end{abstract}

\section{Introduction}

The disposal of municipal solid waste (MSW), which is the discard of matter from human activities, must be done in a proper manner in order to avoid the impact on the environment. Regarding the small community in urban areas, landfill cannot be implemented for the disposal of waste due to the scarcity of land. Onsite treatment by incineration is one of the promising options to treat this waste [1]. However, due to the small capacity of facilities, the burning of waste does not yield enough by-product energy to produce heat or electricity, which causes high operating cost since additional fuel is required to achieve a high destruction temperature [2]. Moreover, with the strengthening emission standards nowadays, many onsite incinerators remain unused [3]. The objective of this work is to redesign and manufacturing of the Green, Eco, Innovative Design and Manufacturing technology of a 1ton per batch MSW in order to use the incinerator at the source of MSW generation. The operating batch time was about 6 to $8 \mathrm{hrs}$ and needed only a one-time charge of MSW into the combustion chamber by using a dumping garbage truck. Only one operator was needed to take care of the system. It was designed to achieve inexpensive operating costs but would be able to attain emission standards which would lead to a Green, Eco and Innovative small-scale MSW incinerator.

\section{General Concept of the Innovative Design of a 1-ton per batch MSW Incinerator}

The general operating principle of the small-scale MSW incinerator consists of charging of MSW in the combustion chamber in a batch process. Each batch is enough to partially burn for 10 to 15 minutes, then the next charging will start to feed the MSW in the chamber again. Advantage of this technique is to help the combustion to be taken place in a short time and can avoid the excess pollutants coming from the primary combustion chamber (PCC) to the secondary combustion chamber (SCC). However, one drawback is that it is a time-consuming process and requires an operator to take care of the incinerator at all times. As a result, an innovative design is to try to avoid this too-frequent feeding time on the incinerator. 


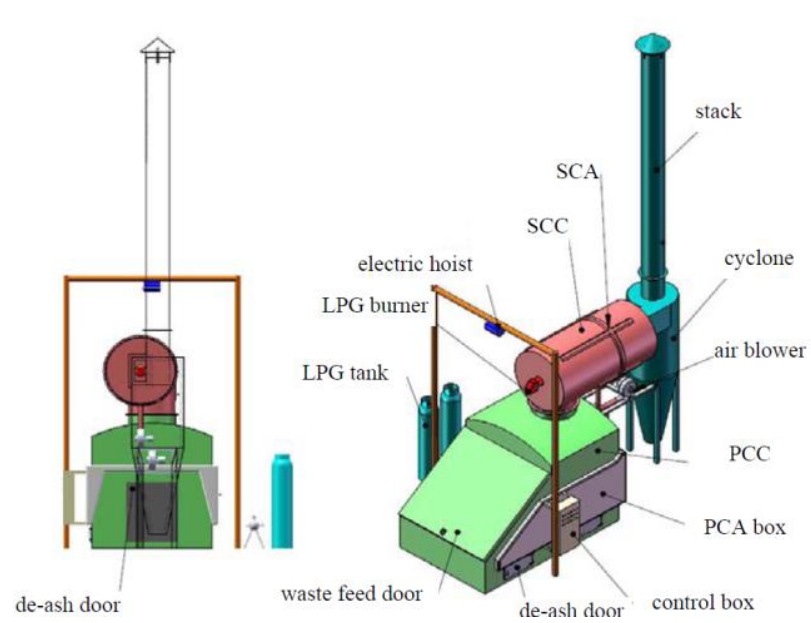

Figure 1. Overview of 1-ton per batch MSW incinerator.

The next consideration is the high operating cost due to the use of an additional fuel burners in the primary combustion chamber. The purpose of this burner is to sustain the desired combustion temperature in the chamber when burning high-moisture waste content, especially with wet fraction MSW (food waste, vegetation waste, etc.) The more that this additional burner is used, the more additional fuel must be used (diesel oil, for example), which results in high operating costs. In order to overcome this, the less use or even no use of the burner muse be taken into account, even by improving the combustion process by using a novel design of combustion air distribution or by mixing the characteristics of waste and air.

In order to achieve complete combustion, not only must the proper ratio of waste and air be matched, but the 3Ts concept of combustion, including Time, Temperature and Turbulence must be implemented during the design of the incinerator [4]. Time ensures enough reaction time between the waste and air, both in the PCC or SCC. The time in the PCC will deal with the solid-phase combustion of the waste and primary combustion air (PCA); it must be long enough to burn all of the carbon contained in the waste, so only a small fraction of carbon will be left in the ash. The Time in the SCC concerns the gas-phase combustion of the flue gas coming from the PCC, which may contain an incomplete combustion product, and this must be re-burnt with secondary combustion air (SCA) and have enough time for complete combustion. Temperature is a control combustion parameter both for the PCC and SCC. The temperature in the PCC must be high enough for completely burning the solid fraction of waste and for transforming it completely into ash. In the SCC, the temperature must be high enough to ensure complete combustion of the flue gas. It is recommended that, for the MSW incinerator, the temperature in both the PCC and SCC must be at least $850^{\circ} \mathrm{C}$ [5]. Turbulence is a mixing characteristic in the combustion chamber in order to ensure complete combustion. In the PCC, turbulence can be performed in terms of the movement of the waste in the chamber or the injection location of the PCA in the PCC, where in the SCC, turbulence means the mixing of the flue gas coming from the PCC and SCA. The degree of mixing in the PCC and SCC can be investigated through the study of the computational fluid dynamic (CFD) [6].

An overview design of the 1-ton per batch MSW incinerator in this study is shown in Figure 1. It consists of three main parts: the PCC, SCC, and cyclone. The MSW will be fed into the PCC through the feed gate which can be opened by an electric hoist. It is charged one time into the PCC and the feed gate will close. The PCA is fed into the PCC through the air box around the body of the PCC. Hot flue gas from the PCC will flow up to the SCC, which is located on the top part and reburned with the SCA, which is fed at the circumference of the SCC in order to increase the degree of mixing. The products of the complete combustion will flow out from the SCC and lead to a cyclone for dust and particulate collection. The cyclone which was selected for use in this study is only one option for controlling dust and particulate. Other alternatives for air pollution control strategy such as a wet scrubber, a bag filter, or an electrostatic precipitator can be implemented based on emission regulations. The designed system uses only one additional burner located at the SCC to ensure the desired combustion temperature in the SCC. No burner is used in the PCC in order to reduce the operating cost of the incinerator. Additional fuel used in this design is LPG, which costs half the price of diesel oil.

\section{Designed Waste Characteristic}

The characteristic of the MSW used for this study came from the average values of developing country's MSW characteristics [1] which shown in Table 1 :

Table 1. Design waste characteristic

\begin{tabular}{|l|l|}
\hline Moisture: $32 \%$ & Ash: $7 \%$ \\
\hline $\begin{array}{l}\text { Heating Value: } 14,700 \mathrm{~kJ} / \mathrm{kg} \\
\text { (dry basis) }\end{array}$ & Bulk Density: $200 \mathrm{~kg} / \mathrm{m}^{3}$ \\
\hline
\end{tabular}

\section{Innovative Design and Manufacturing of feeding system}

In order to design the charging of the MSW into PCC in one batch, it is recommended to use the charging of waste from a dump garbage truck returning from collecting waste from households. The MSW will be dumped into the PCC at one time. Since the desired capacity of the dumping is one ton per batch with a bulk density of waste of $200 \mathrm{~kg} / \mathrm{m}^{3}$, the MSW volume in one batch is $5 \mathrm{~m}^{3}$. However, the volume of the PCC must be at least 2 times the MSW volume in the chamber in order to have enough space for the combustion process, and consequently, the design volume of the PCC will be $10 \mathrm{~m}^{3}$. Knowing the width of the garbage dump truck, the dimension of the PCC can be determined. The opening of the feed gate is designed as a hinge, which is opened by a one-ton electric hoist. After the charging process completed, it will be closed before the ignition process begins. 


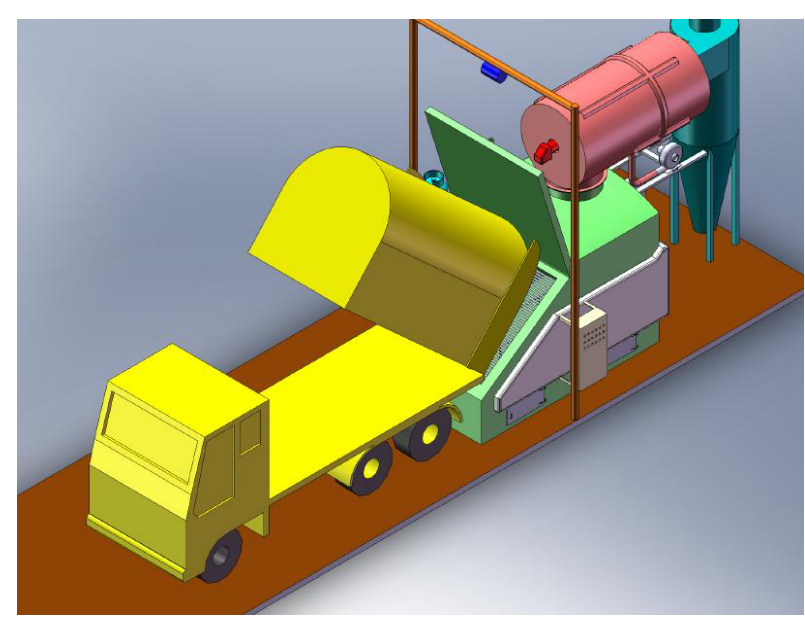

Figure 2. Feeding of MSW into the PCC using a garbage dump truck

\section{Innovative Design of PCC and SCC}
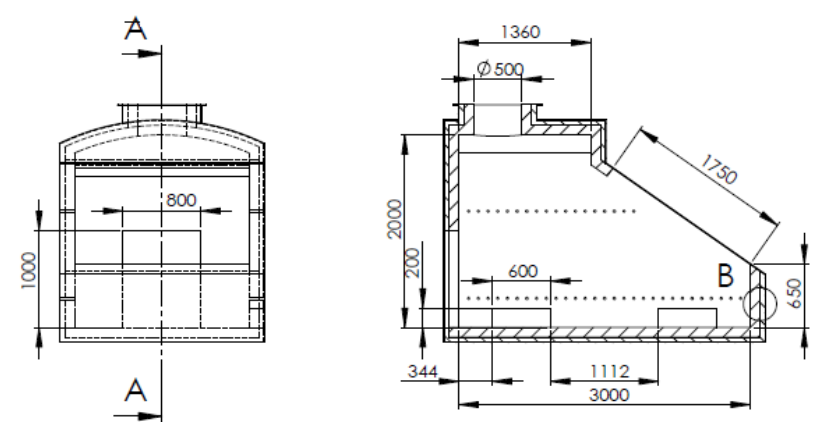

(a)

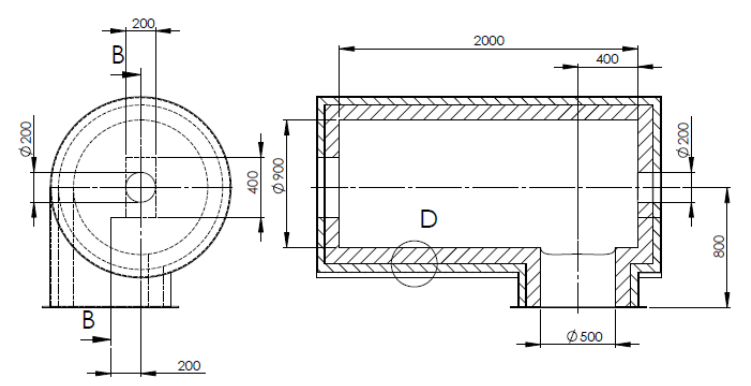

(b)

Figure 3. A design of innovative 1 Ton per day incineration system (units in $\mathrm{mm}$.)

Figure 3 shows the design of the PCC and SCC. Waste will be charged in the PCC and will sit on the grating, which is made of cast iron, in order to sustain a high temperature during the combustion. The grating is placed about $10 \mathrm{~cm}$ above the PCC's floor. Ash, which is a result of the combustion, will fall between the spaces of the grating to the floor. The doors on the side of the PCC are used to remove the ash. The PCA coming from an air blower will be distributed and injected into PCC through multi-holes on both sides. There are two levels of air holes; the lower holes are used for combustion of the air of solid waste putting on the grate, and the upper holes are used to provide additional air to burn the volatile matter evaporated from the solid bed. Each row of air holes will have valves to freely control the combustion process and can be regulated by the operator. The SCC is located on the top of the PCC and put in a location so that the flue gas coming from the PCC will flow circumferentially into the SCC in order to increase the degree of mixing to meet the turbulence requirements for complete combustion. The SCA also comes from another air blower and is injected into the SCC as a ring around the circumference of the SCC wall. The volume of the SCC is designed to have a residence time for the gas retained in the chamber longer than 1 second.

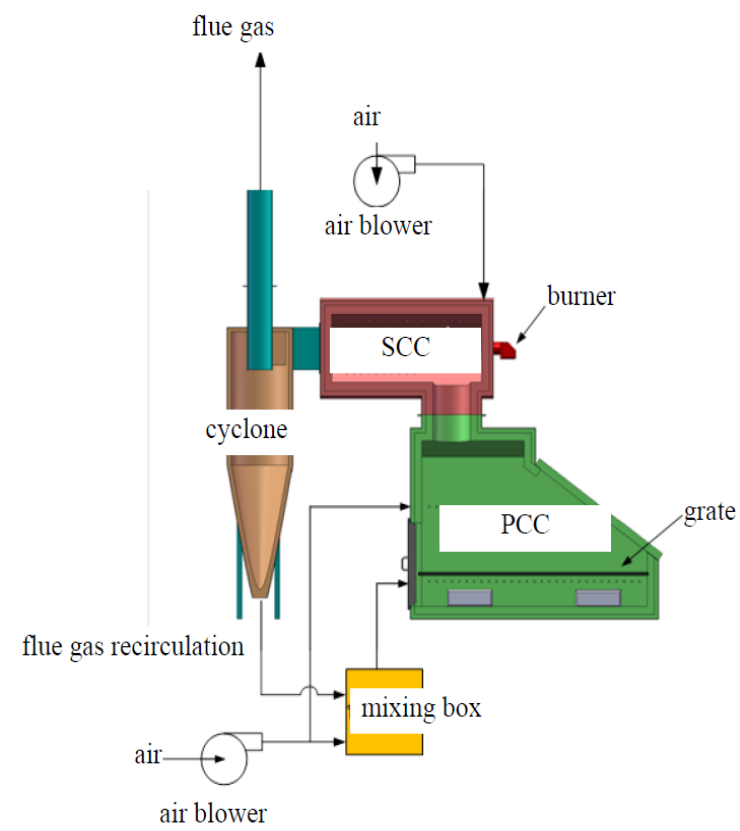

Figure 4. Innovative design for the recirculation of hot flue gas for reburning in the PCC

The designed system uses only one additional LPG burner installed at the SCC. Its function is only to assure the reaching of the desired SCC temperature $\left(850^{\circ} \mathrm{C}\right)$ by igniting the LPG as additional fuel. Once it reaches the desired temperature, the burner will stop the injection of the LPG but will feed only combustion air. Energy savings could be accomplished by recirculating the hot flue gas from the cyclone and reverting it to mix with the PCA in the mixing box before being injected into the PCC, and therefore, installation of a PCC burner is not required (Figure 4). Ignition of the MSW in the PCC can be done by igniting it with a match and a small amount of gasoline poured on top of the waste in the PCC. The PCC and SCC wall consists of three layers. The inner layer is made of castable refractory, which can sustain a combustion temperature up to $1,400^{\circ} \mathrm{C}$ with a thickness of $10 \mathrm{~cm}$. The second layer is a thermal insulator used to keep the heat inside the chamber and can sustain a temperature up to $1,100^{\circ} \mathrm{C}$ with a thickness of $5 \mathrm{~cm}$. The outer layer is a steel structure with a thickness of $4.5 \mathrm{~mm}$.

The design criteria for the Green, Eco, Innovative Design and Manufacturing Technology of one-ton per batch MSW incinerator can be summarized as follows: 
- The destruction capacity of the combustor is one ton per batch for $14,700 \mathrm{~kJ} / \mathrm{kg}$ (dry basis) heating value of waste

- The dumping of the waste into the incinerator from the garbage truck has been applied for only a one-time feed

- The combustion air in the PCC is divided into upper fire and under fire for complete combustion of the MSW

- Only one additional burner is used at the SCC and for the recirculation of the hot flue gas for reburning

- It is designed for one-time feed of MSW with a batch operating time of 6 to $8 \mathrm{hrs}$ with one operator

\section{Summary}

A small-scale one-ton per batch MSW incinerator with a green, eco, and innovative design concept and manufacturing technology has been established. The idea is to use this design unit at the source of waste with lower operating and maintenance costs, less need of an operator to operate and control it, but still achieve a good combustion process and less impact on the environment. The one-time feed of waste into the combustion chamber leads the non-use of an auxiliary burner in the primary combustion chamber. The 3Ts concept of complete combustion has been achieved via innovative design and manufacturing.

\section{References}

1. K. Laohalidanond, P. Chaiyawong, S. Kerdsuwan, Municipal Solid Waste Characteristics and Its Green and Clean Energy Recovery in Megacity of Asian Countries, 2015 International Conference on Alternative Energy in Developing Countries and Emerging Economies, Bangkok, 2015

2. S. Kerdsuwan, Innovative Design and Manufacturing Technology of High Temperature Air Combustion (HTAC) Municipal Solid Waste Incinerator, Applied Mechanics and Materials Vols. 789-790 (2015) pp 375-379

3. S. Kerdsuwan, K. Laohalidanond, W. Jangsawang, Sustainable Development and Eco-friendly Waste Disposal Technology for the Local Community, 2015 International Conference on Alternative Energy in Developing Countries and Emerging Economies, Bangkok, 2015

4. S. Kerdsuwan, K. Laohalidanond, P. Chaiyawong, $A$ Novel Hybrid Design of Incineration - Gasification for Energy Saving, Applied Mechanics and Materials Vols. 799-800 (2015) pp 95-99

5. C. R. Brunner, Incineration Systems Handbook, McGraw-Hill, (New York, NY), 1991

6. P. Meenaroch, S. Kerdsuwan, K. Laohalidanond, Development of Kinetics Models in Each Zone of a $10 \mathrm{~kg} / \mathrm{hr}$ Downdraft Gasifier by Using Computational Fluid Dynamics, 2015 International Conference on Alternative Energy in Developing Countries and Emerging Economies, Bangkok, 2015 